\title{
Modulate the Effects of the Bone Marrow-Derived Mesenchymal Stem Cells' Supernatant on Neutrophil Functions by 17-beta Estradiol
}

\author{
Nekoeii Z. ${ }^{1}$ BSc, Afzal Ahangran N.* PhD, Delirejh N. ${ }^{1}$ PhD \\ *Microbiology Department, Veterinary Faculty, Urmia University, Urmia, Iran \\ ${ }_{1}^{1}$ Microbiology Department, Veterinary Faculty, Urmia University, Urmia, Iran
}

\begin{abstract}
Aims: Bone marrow-derived mesenchymal stem cells have therapeutic potentials due to their immunomodulatory properties. Estrogen is also an immunomodulator. The current study was to analyze the effect of bone marrow-derived mesenchymal stem cells' supernatant of male rats adjacent with estrogen on the function and survival of neutrophils.

Materials \& Methods: In this experimental study, mesenchymal stem cells isolated from the femur and tibia of the bone marrow of male 6-8 week old rats were cultured in DMEM. After maturation, the supernatant of the mesenchymal stem cells treated with estrogen (10nM and $20 \mathrm{nM})$ and cultured for 72 hours at $37^{\circ} \mathrm{C}$. Then, the mesenchymal stem cells were co-cultured with the peripheral blood neutrophils and the neutrophil functions were measured by phagocytosis and respiratory burst (Nitro Blue Tetrazolium resuscitation) tests. The viability of neutrophils was measured with acridine-orange fluorescent staining. Data were analyzed by SPSS 18 software, using independent T, one way ANOVA and Tukey tests.

Findings: The respiratory burst in the groups treated with $10 \mathrm{nM}$ and $20 \mathrm{nM}$ of estrogen showed significant difference compared with the control group. The percentage of phagocytosis in the groups treated with $10 \mathrm{nM}$ and $20 \mathrm{nM}$ of estrogen were significantly increased compared with the control group. There was a significant difference between the percentage of phagocytosis of $10 \mathrm{nM}$ and $20 \mathrm{~nm}$ groups $(\mathrm{p}<0.05)$. The apoptosis level in the groups treated with $10 \mathrm{nM}$ and $20 \mathrm{nM}$ of estrogen showed significant difference compared with the control group.

Conclusion: Supernatant of mesenchymal stem cells treated with estrogen increases the phagocytosis potential and respiratory explosion of neutrophils.
\end{abstract}

\section{Keywords}

Mesenchymal Stromal Cells [http://www.ncbi.nlm.nih.gov/mesh/68059630];

Estrogens [http://www.ncbi.nlm.nih.gov/mesh/68004967];

Neutrophils [http://www.ncbi.nlm.nih.gov/mesh/68009504]

\footnotetext{
* Corresponding Author

Tel: +984432770508

Fax: +984432771926

Address: Microbiology Department, Veterinary Faculty, Nazlu Pardis, Kilometer 11 of Sarv Road, Urmia, Iran

n.a.ahangran@gmail.com

Received: November 25, $2014 \quad$ Accepted: May 10, 2015 ePublished: June 20, 2015
} 


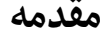

مغز استخوان داراى دو نوع سلول است؛ سلولهاى بنيادى مزانشيمى (MSC) و سلولهاى خونساز يا هماتويويتيك [1]. سلولى است با توانيى تقسيم زياد كه تحت شرايط مناسب

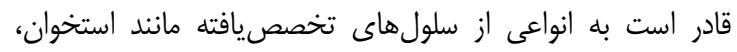

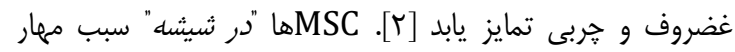

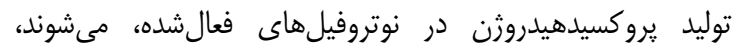
بنابراين مىتوانند بهطور بالقوه شدت انفجار تنفسى را تحت شرايط

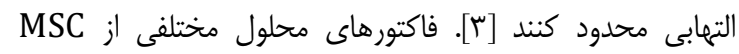

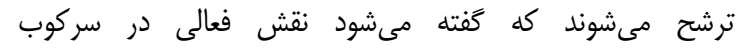

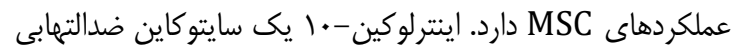
است كه در بسيارى از بروسههاى سركوبكرى نقش دارد، بنابراين

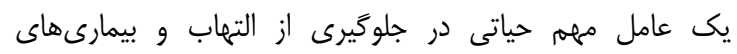

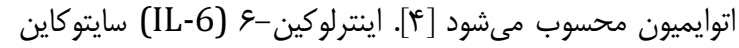
ديكرى است كه مىتواند بلوسيله MSC توليد شود و روى اثرات

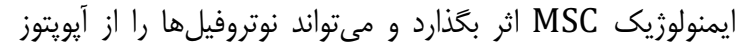

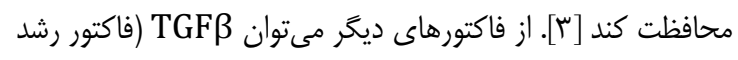

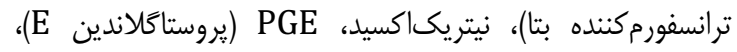
HLA-G5 HGF دادهاند كه MSC ممكن است از القاى آيويتوز در لنفوسيتها محافظت كند و حتى مشاهده شده است كه مىتواند تيموسيتها و و

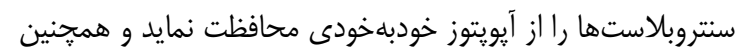

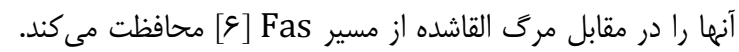
بررسى اثر استروثن بر توليد سايتوكاين بلهوسيله سلولهاى

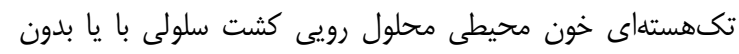

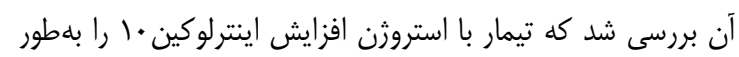

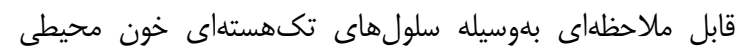

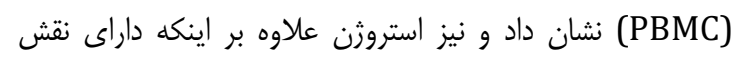

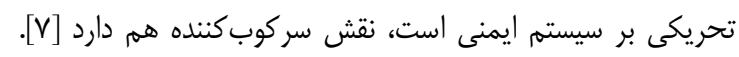

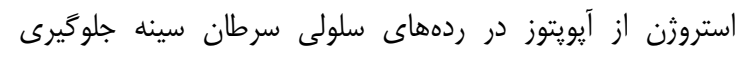

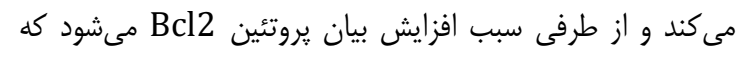

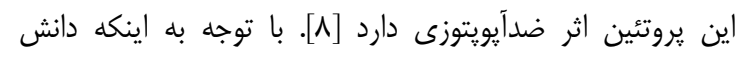

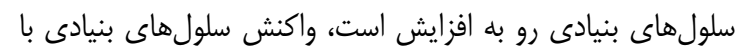

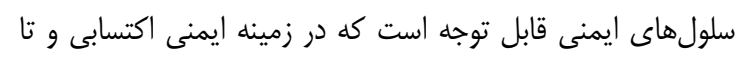

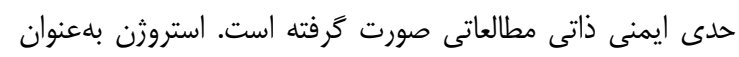

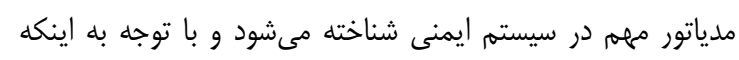

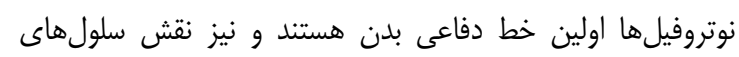

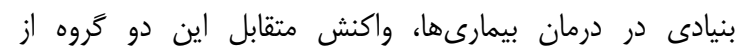

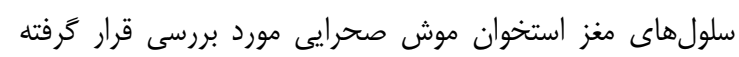

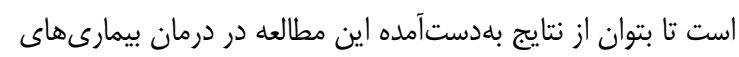
مرتبط با استفاده از تكنيك سلولدرمانى استفاده كرد و زمينه
تعديل اثرات مايع رويى حاصل اندارئ سلولهاى

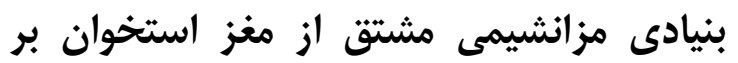

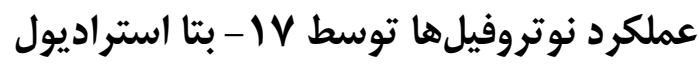

\author{
زهرا نكويى BSc \\ كروه ميكروبيولوزى، دانشكده داميزشكى، دانشخاه اروميه، اروميه، ايران

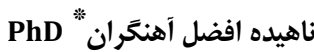 \\ كروه ميكروبيولوزى، دانشكده داميزشكى، دانشخاه اروميه، اروميه، ايران \\ PhD نوروز دليرز \\ كروه ميكروبيولوزى، دانشكده داميزشكى، دانشخاه اروميه، اروميه، ايران
}

جكيده

اهداف: سلولهاى مزانشيمى مشتقشده از مغز استخوان بلددليل خاصيت

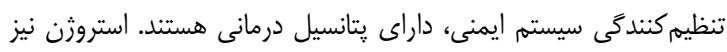

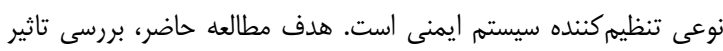

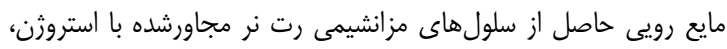
بر عملكرد و ميزان زندهمانى نوتروفيل بود.

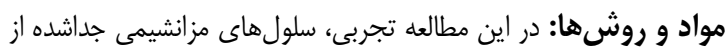

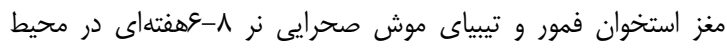

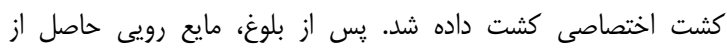

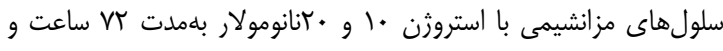

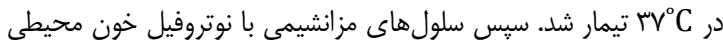

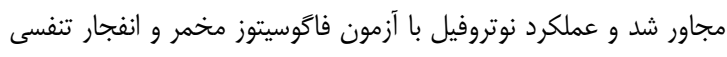

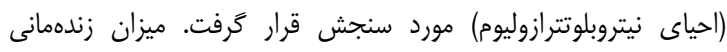

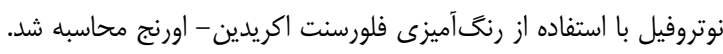

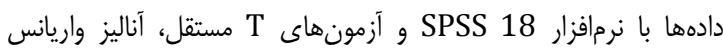
يكىطرفه و توكى آناليز شدند.

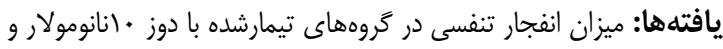

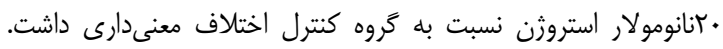

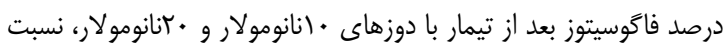

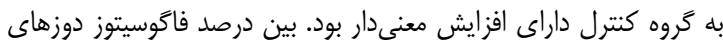

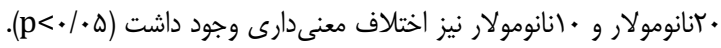

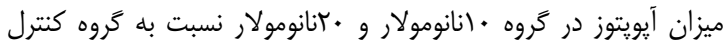

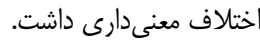
نتيجه كَيرى: مايع رويى سلولهاى مزانشيمى مجاورشده با استروثن

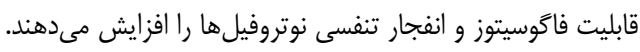

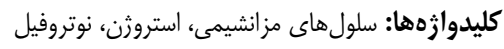

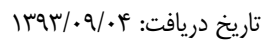

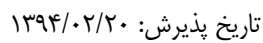

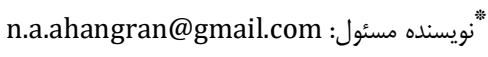

دوره آץ، شماره r، تابستان FqF

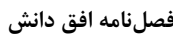




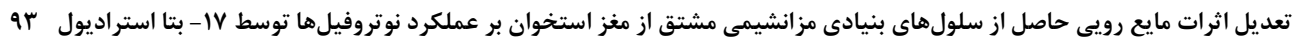

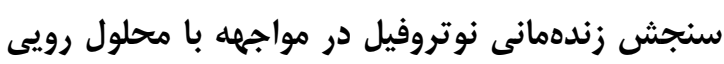

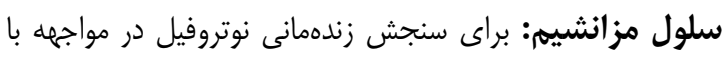

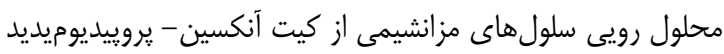
(Sigma Aldrich, Cat NO: 51-6710AK) استفاده شد. يس از دو بار شستوشوى سلول نوتروفيل انكوبهشده

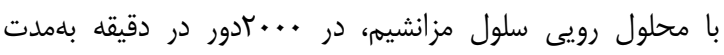

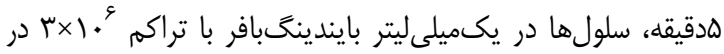

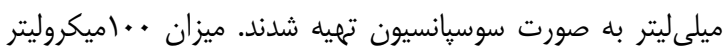
از سوسيانسيون فوق با هميكروليتر اكريديناورنج (سيخما؛ ايالات

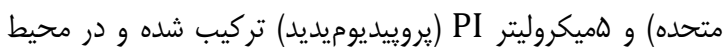

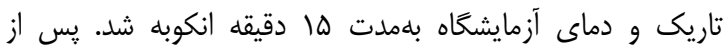

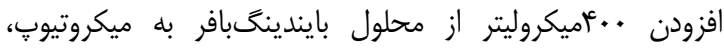

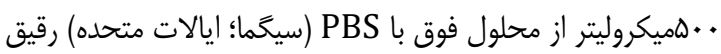

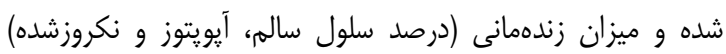

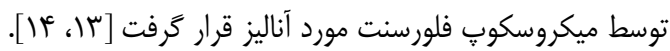

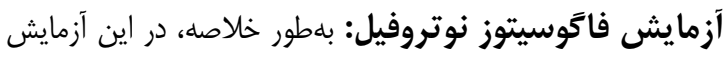

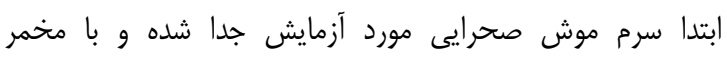

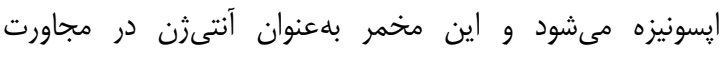

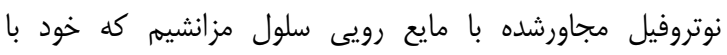

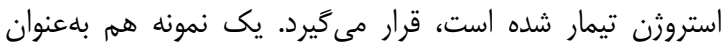

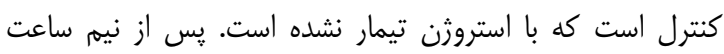

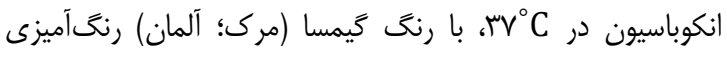

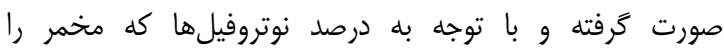

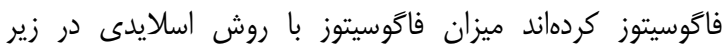

ميكروسكوب نورى بررسى مى شود [10].

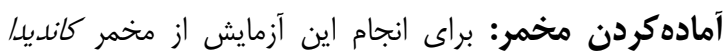

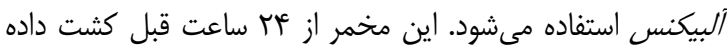

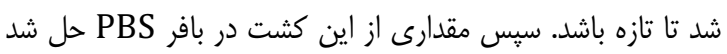

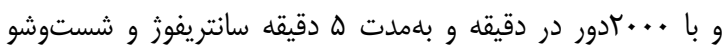

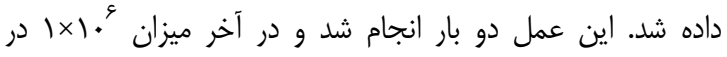

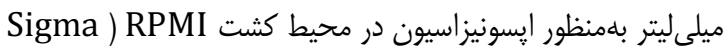
Aldrich

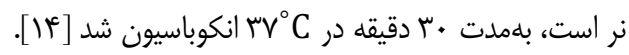

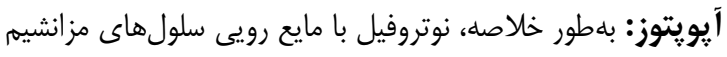

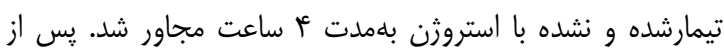

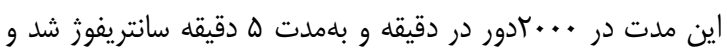

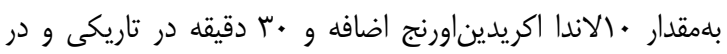

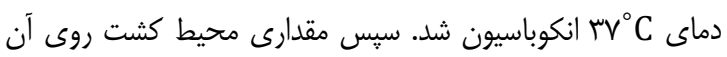

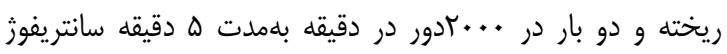

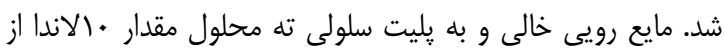

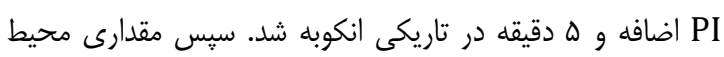

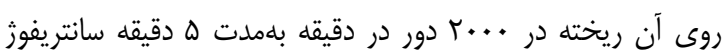

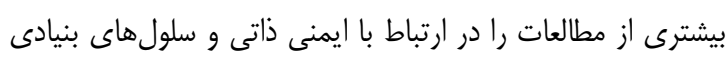

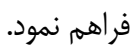
مطالعه حاضر با هدف بررسى تاثير مايع رويى حاصل از سلولهاى

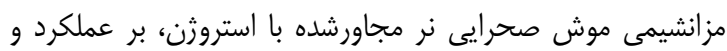
ميزان زندهمانى نوتروفيل انجام شد.

مواد و روشا هازيا جداسازى و كثت سلول بنيادى مزانشيه: مراحل كشت و

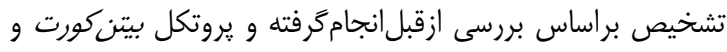

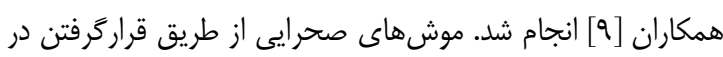

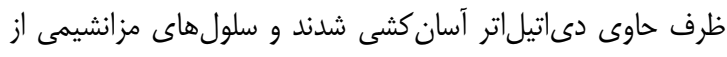

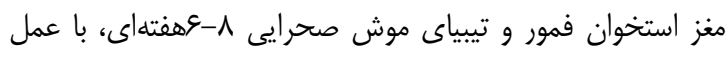

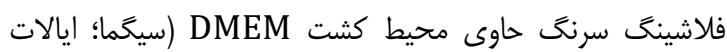

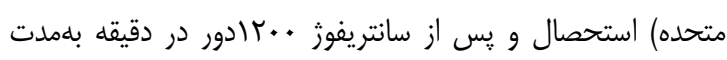

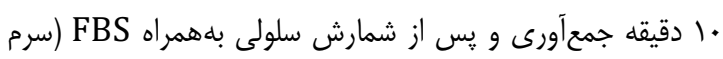

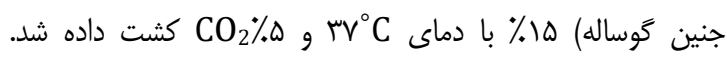

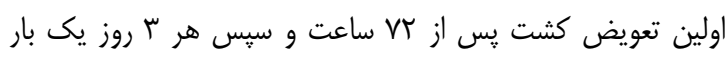

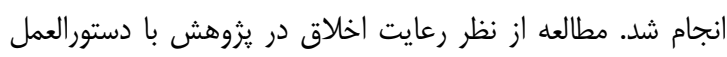
انجمن حمايت از حيوانات مطابقت داشت.

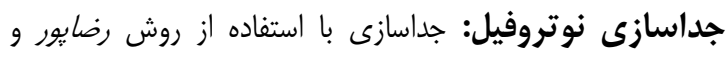

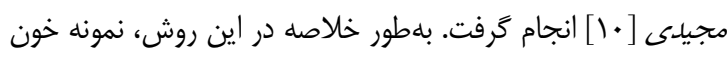

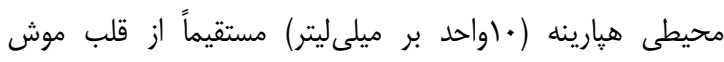

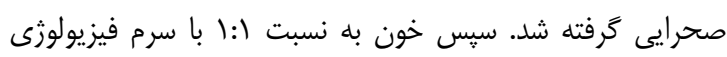

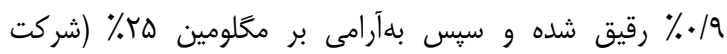

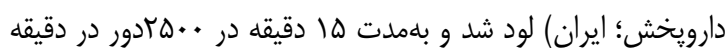

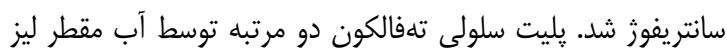

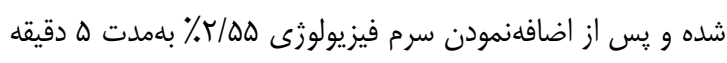

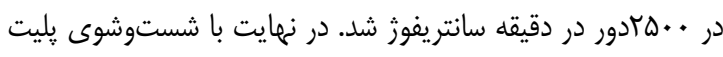

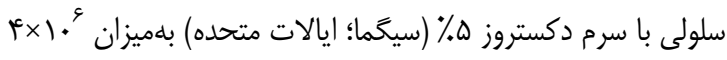

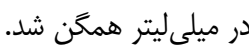

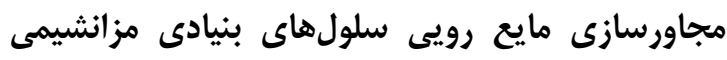

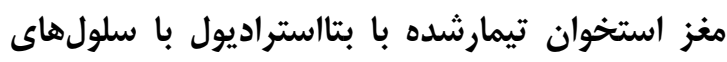

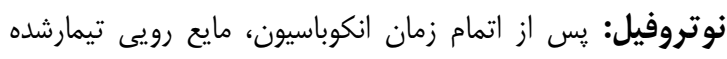

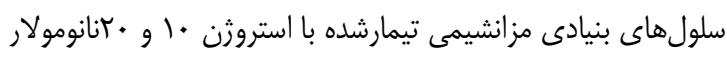
[11] موجود در فلاسك در يك لوله فالكن هاميلىليتر استريل

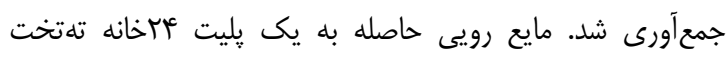

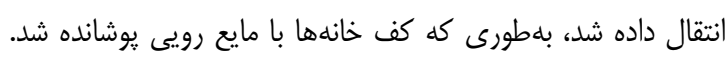

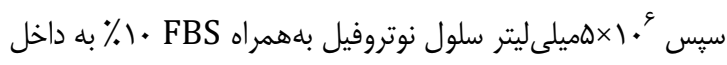

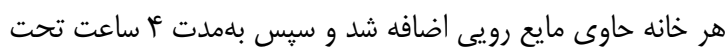

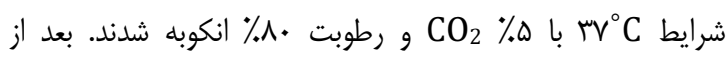

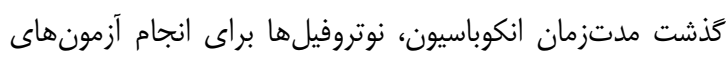

تكميلى جداسازى شدند [1 آ] 


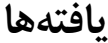

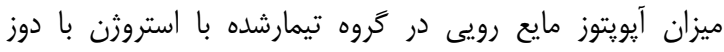

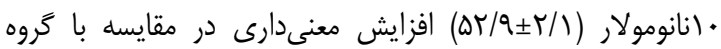
كنترل (ا/

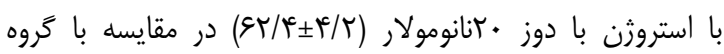

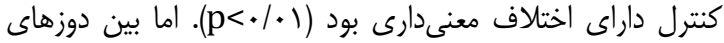
• بنانومولار و • انانومولار اختلاف معنى دارى وجود نداشت.

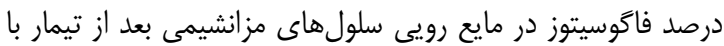

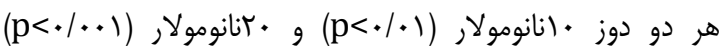

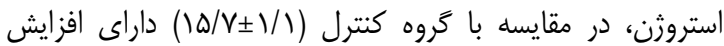

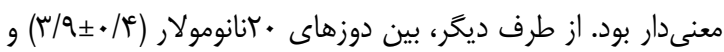

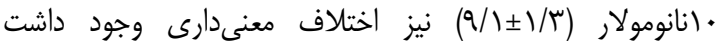
.$(p<\cdot / \cdot \Delta)$ ميزان انفجار تنفسى در نوتروفيل مجاورشده با مايع رويى

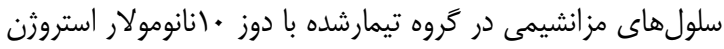

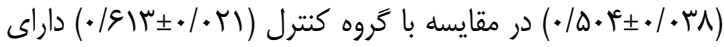

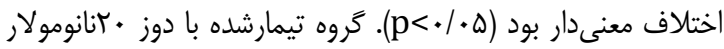
استروزن (qץ./•

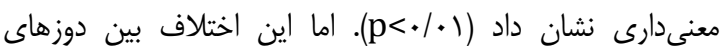
• بنانومولار و • انانومولار استروثن معنىدار نبود.

بحث سلولهاى بنيادى مزانشيمى در محيط داخلى مغز استخوان در

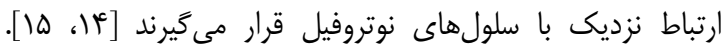
سلولهاى نوتروفيل بالغ، محيط داخلى مغز استخوان را ترك كردها و به سمت خون حركت مى كنند. با اين وجود ارتباط مستقيم بين سلولهاى بنيادى مزانشيمى و نوتروفيلهاى بالغ در محيط داخلى

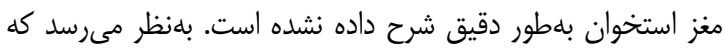
اين سلولها در حفاظت سلولهاى نوتروفيل از مركى زودرس و و مهار فعالسازى آنها در محيط داخلى مغز استخوان نقش دارن الندان

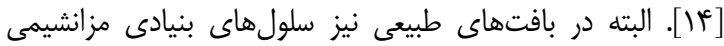

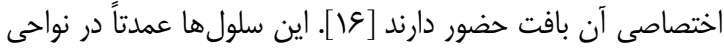
مختلفى از قبيل نواحى اطراف سلولهاى اندوتليال (يرى اندوتليال) و

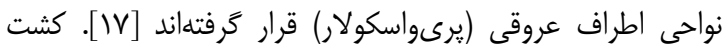
سلولهاى نواحى اطراف عروقى مشتق از بافتهاى مختلف، يك إنى

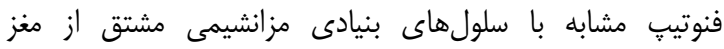

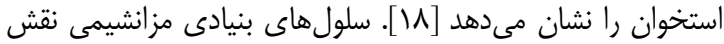
ايمونومودلاتورى در مكانيزمهاى دفاعى اصلى در برابر واكنشهاى إنى

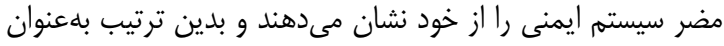

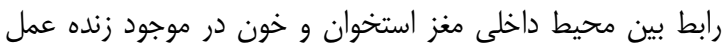

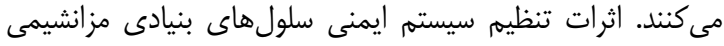
نيازمند فعالسازى اوليه آنها با سلولهاى سيستم ايمنى از قبيل

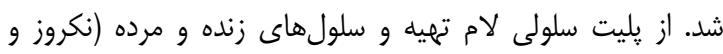

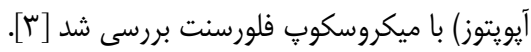
روش انجام آزمايش بيكانهخوارى: براى انجام اين آزمايش إني

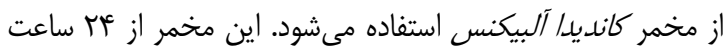

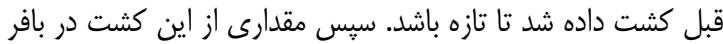
PBS

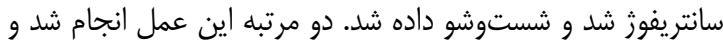

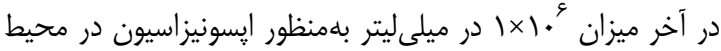
كشت RPMI كه داراى • (\% سرم تازه موش صحرايى نر است،

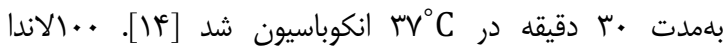

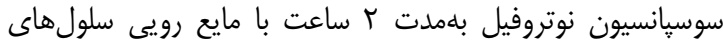

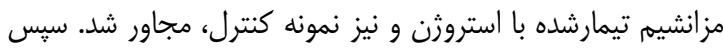
از اين سوسبانسيون روى لام استريل ريخته و ...اميكروليتر از

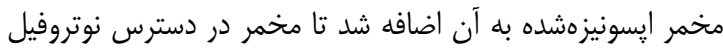

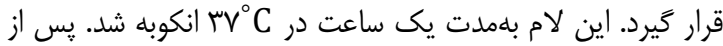

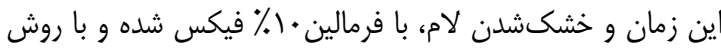

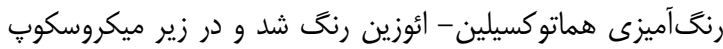

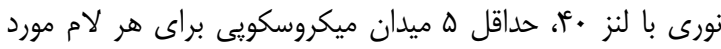

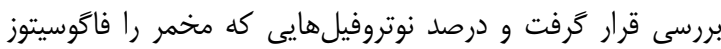

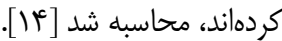
آزمايش احياى نيتروبلوتترازوليوم (NBT): اين آزمايش

براى سنجيدن ميزان توليد واسطههاى فعال اكسيثن در سلول

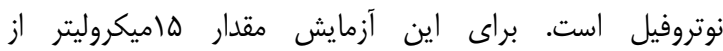

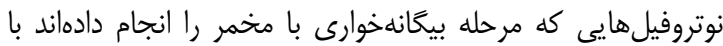

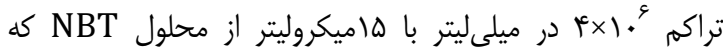

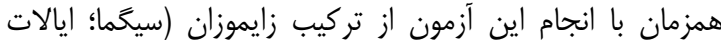

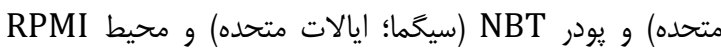

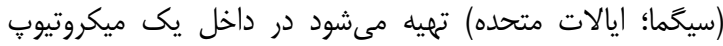

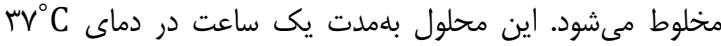

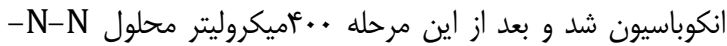

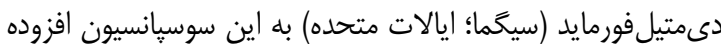

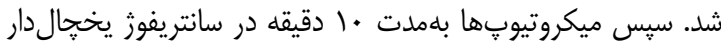

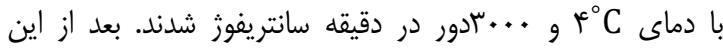

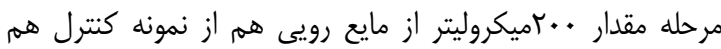

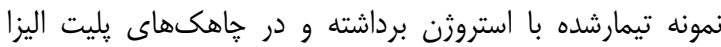

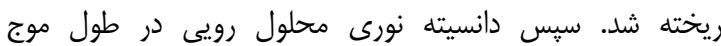

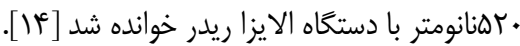

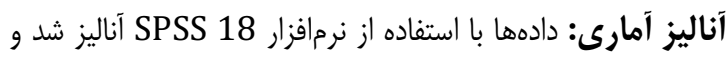

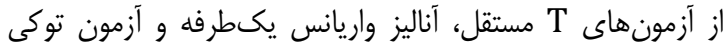
براى كروه محلول رويى سلول مزانشيمى استفاده شد. دادهائا

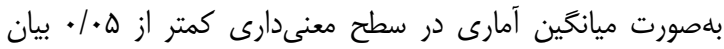

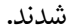




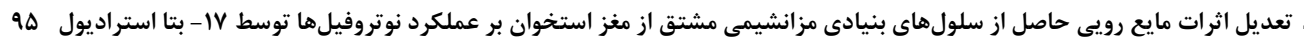

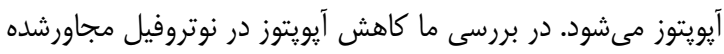

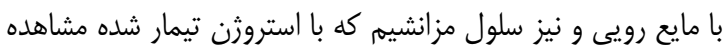

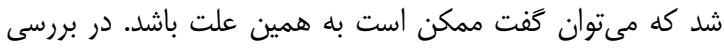

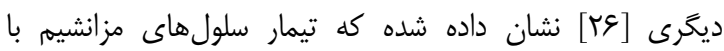

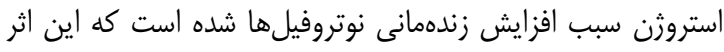

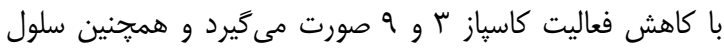

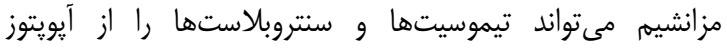

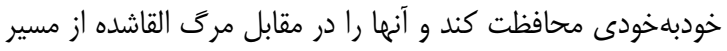
Fas نوتروفيل با همين مكانيزم اعمال مى كند.

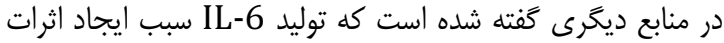

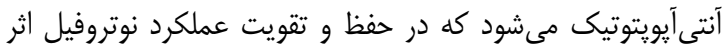

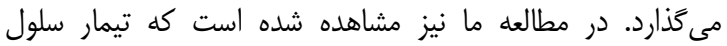

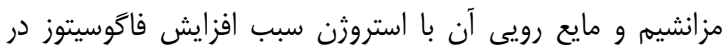
ك-وتروفيل شده است كه مىتوان كفت احتمالاً اين اثر بهدليل تولئ فاليد IL-6 STAT-3

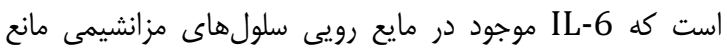

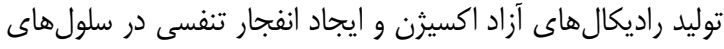

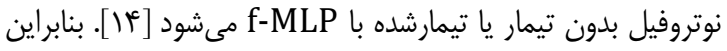

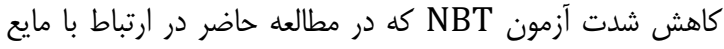
رويى مشاهده شد ممكن است از اين طريق صورت كرفنته باشد.

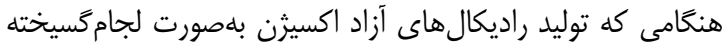

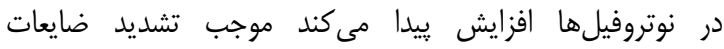

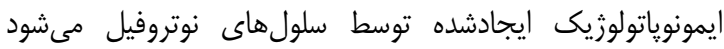

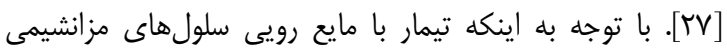

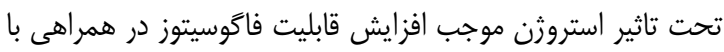

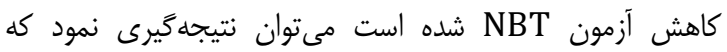
نوتروفيلها يك فنوتيّ ضدالتهابى يبيدا كرده و مى إتوانند بهديليل

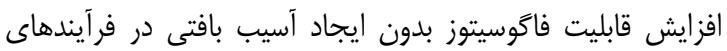
ترميم بافت مشاركت كنند.

نتايج مطالعه حاضر بلهور جالب توجهى نشان داد داد كه تيمار

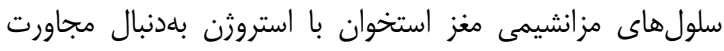
مستقيم سلولى موجب افزايش معنىدار قابليت فاكوسيتوز و انفجار

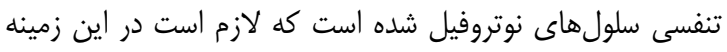

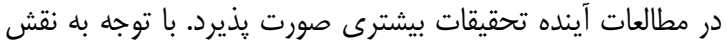

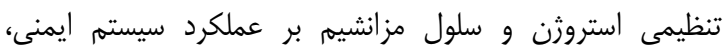
برهمكنش نوتروفيل با مايع رويى حاصل از سلول مزانشيمى مى مئ-

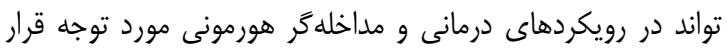

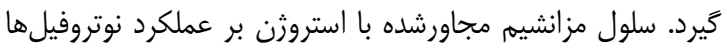

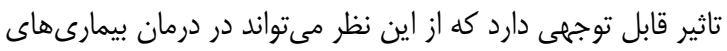

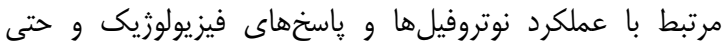

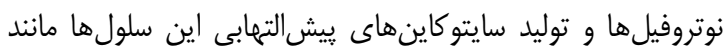
TNF $\alpha$

$[r \cdot$

بعد از فعالسازى، سلولهاى بنيادى مزانشيمى بهواسطه توليد

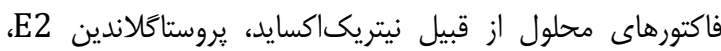

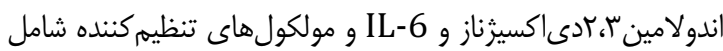

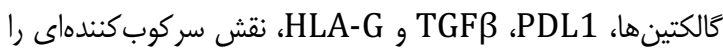

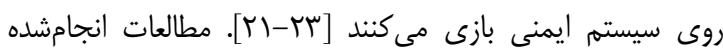

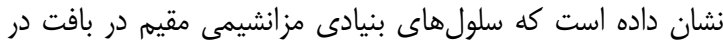

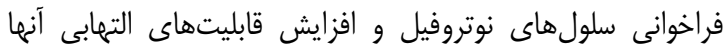

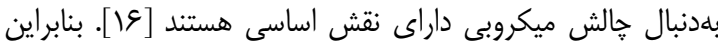

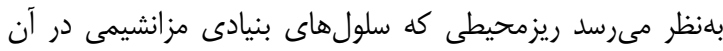

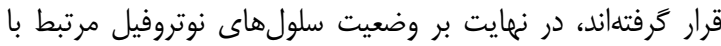

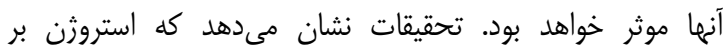

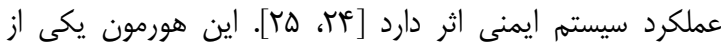

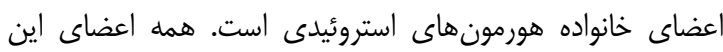

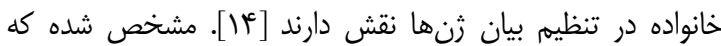

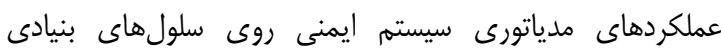

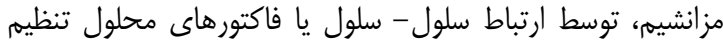

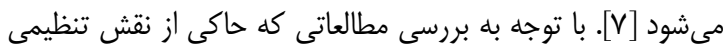

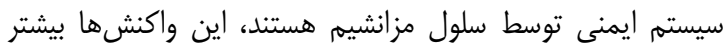
مرتبط با ارتباط سلول- سلول بوده و در مر مورد مايع رويى سلول اطلاعات كمى در دسترس است.

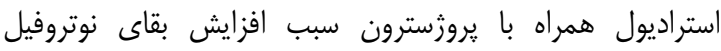
مىشود كه اين عمل از طريق تاخير در آيويتوز با كاهش فعاليت

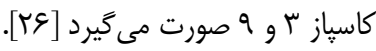
هموستاز سلولهاى نوتروفيل در بدن توسط آيويتوز تنظيم مى شود.

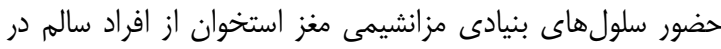

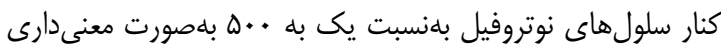

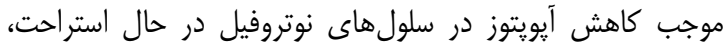

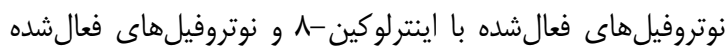

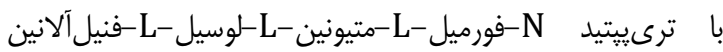

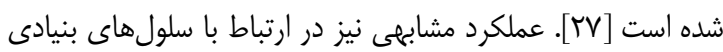
مزانشيمى بافتهاى محيطى كزارش شده است [M [IN]. تحقيقات

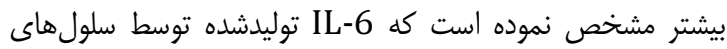
بنيادى مزانشيمى موجب افزايش بقا و مهار آيويتوز درسلولهاى

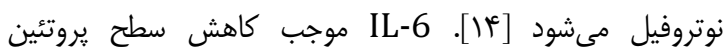
ييشآيويتوزى Bax و افزايش يروتئين ضدآيويتوزى سلولهاى نوتروفيل مىشود [عَ، تYV].

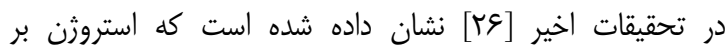

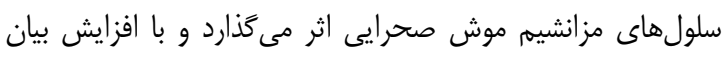
رنومى مولكولهاى BCL-2 و BCL-XL سبب ممانعت از عمل فرائ 
12- Esmaili Gouvarchin Galeh H, Delirezh N. Calcitriol modulates the effects of the supernatants of bonemarrow-derived mesenchymal stem cells on neutrophil functions. Turk J Biol. 2014;38(3):365-70.

13- Turina M, Miller FN, Mc Hugh PP, Cheadle WG, Polk HC. Endotoxin inhibits apoptosis but induces primary necrosis in neutrophils. Inflammation. 2005;29(1):55-63. 14- Ghoseiri R, Alizadeh S, Mojtahedzadeh F, Najafi Poor H. Survey of the effect of powder nigella sativa (black seed) in increscent of monocyte phagocytosis in quinea pig. Horizon Med Sci. 2010;16(3):55-64. [Persian]

15- Hamaliaka A, Novikova I. Nitric oxide production disorders in leukocytes of patients with recurrent furunculosis. Biomed Pap Med Fac Univ Palacky Olomouc Czech Repub. 2010;154(2):367-72.

16- Glennie S, Soeiro I, Dyson PJ, Lam EW, Dazzi F. Bone marrow mesenchymal stem cells induce division arrest anergy of activated T cells. Blood. 2005;105(7):2821-7.

17- Corcione A1, Benvenuto F, Ferretti E, Giunti D, Cappiello V, Cazzanti F, et al. Human mesenchymal stem cells modulate B-cell functions. Blood. 2006;107(1):36772.

18- Spaggiari GM, Capobianco A, Becchetti S, Mingari MC, Moretta L. Mesenchymal stem cell-natural killer cell interactions: evidence that activated NK cells are capable of killing MSCs, whereas MSCs can inhibit IL-2-induced NK-cell proliferation. Blood. 2006;107(4):1484-90.

19- Brandau S, Jakob M, Hemeda $H$, Bruderek $K$, Janeschik S, Bootz F, et al. Tissue-resident mesenchymal stem cells attract peripheral blood neutrophils and enhance their inflammatory activity in response to microbial challenge. J Leukoc Biol. 2010;88(5):1005-15.

20- Aggarwal S, Pittenger MF. Human mesenchymal stem cells modulate allogeneic immune cell responses. Blood. 2005;105(4):1815-22.

21- Beyth S, Borovsky Z, Mevorach D, Liebergall M, Gazit $\mathrm{Z}$, Aslan $\mathrm{H}$, et al. Human mesenchymal stem cells alter antigen-presenting cell maturation and induce T-cell unresponsiveness. Blood. 2005;105(5):2214-9.

22- Ghannam S, Bouffi C, Djouad F, Jorgensen C, Noël D. Immunosuppression by mesenchymal stem cells: mechanisms and clinical applications. Stem Cell Res Ther. 2010;1(1):2.

23- Maby El Hajjami H, Amé Thomas $\mathrm{P}$, Pangault $\mathrm{C}$, Tribut O, De Vos J, Jean R, et al. Functional alteration of the lymphoma stromal cell niche by the cytokine context: Role of indoleamine-2,3 dioxygenase. Cancer Res. 2009;69(7):3228-37.

24- Ansar Ahmed S, Dauphinée MJ, Montoya AI, Talal N. Estrogen induces normal murine CD5+B cells to produce autoantibodies. J Immunol. 1989;142(8):2647-53.

25- Schilling T, Ebert R, Raaijmakers N, Schütze N, Jakob F. Effects of phytoestrogens and other plant-derived compounds on mesenchymal stem cells, bone maintenance and regeneration. J Steroid Biochem Mol Biol. 2014;139:252-61.

26- Blesson CB. Estrogen receptors in leukocytespossible impact on inflammatory processes in the female reproductive system. In: Aimaretti G, Marzullo P, Prodam $\mathrm{F}$, (editors). Endocrinology and metabolism update on mechanisms of hormone action: Focus on metabolism, growth and reproduction. Rijeka, Croatia: InTECH; 2011. 27- Krasnodembskaya A, Song Y, Fang X, Gupta N, Serikov V, Lee JW. Antibacterial effect of human mesenchymal stem cells is mediated in part from secretion of the antimicrobial peptide LL-37. Stem Cells. 2010;28(12):2229-38.

$$
\begin{aligned}
& \text { پاتولوزيك نوتروفيلها در عمل متقابل با سلولهاى مزان مانشيم مورد } \\
& \text { توجه قرار گيرد. } \\
& \text { نتيجه تيرى } \\
& \text { مايع رويى سلولهاى مزانشيمى مجاورشده با استروثن قابليت }
\end{aligned}
$$

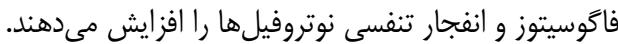

$$
\begin{aligned}
& \text { تشكر و قدردانى: بدين وسيله از زحمات و همكارى كليه } \\
& \text { مسئولان و كاركنان ذىربط بخش ايمنىشناسى و مركز كشت } \\
& \text { سلول دانشكده داميزشكى دانشگاه اروميه تشكر و قدردانى مى شود. }
\end{aligned}
$$

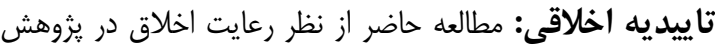

$$
\begin{aligned}
& \text { با دستورالعمل انجمن حمايت از حيوانات مطابقت داشت. } \\
& \text { تعارض منافع: موردى توسط نويسندكان گزارش نشده است. } \\
& \text { منابع مالى: مطالعه حاضر حاصل پاياننامه مقطع كارشناسىارشد } \\
& \text { بوده كه با همكارى مركز كشت سلول دانشكده داميزشكى دانشعاه مانهاه }
\end{aligned}
$$

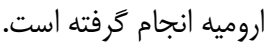

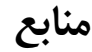

1- Yin T, Li L. The stem cell niches in bone. J Clin Invest. 2006;116(5):1195-201.

2- Beresford JN. Osteogenic stem cells and the stromal system of bone and marrow. Clin Orthop Relat Res. 1989;(240):270-80.

3- Raffaghello L, Bianchi G, Bertolotto M, Montecucco F, Busca A, Dallegri F, et al. Human mesenchymal stem cells inhibit neutrophil apoptosis: A model for neutrophil preservation in the bone marrow niche. Stem Cells. 2008;26(1):151-62.

4- O'Garra A, Barrat FJ, Castro AG, Vicari A, Hawrylowicz C. Strategies for use of IL-10 or its antagonists in human disease. Immunol Rev. 2008;223:114-31.

5- Xu G, Zhang Y, Zhang L, Ren G, Shi Y. The role of IL-6 in inhibition of lymphocyte apoptosis by mesenchymal stem cells. Biochem Biophys Res Commun. 2007;361(3):745-50.

6- Benvenuto F, Ferrari S, Gerdoni E, Gualandi F, Frassoni $\mathrm{F}$, Pistoia $\mathrm{V}$, et al. Human mesenchymal stem cells promote survival of $\mathrm{T}$ cells in a quiescent state. Stem Cells. 2007;25(7):1753-60.

7- Gaillard RC, Spinedi E. Sex-and stress-steroids interactions and the immune system: Evidence for a neuroendocrine-immunological sexual dimorphism. Domest Anim Endocrinol. 1998;15(5):345-52.

8- Hashemi M, Kroczak TJ. Apoptosis in autoimmune diseases. Curr Med Chem. 2005;4(4):429-37.

9- Bittencourt RAC, Pereira HR, Felisbino SL, Murador P, Oliveira APE, Deffune E. Isolation of Bone marrow mesenchymal stem cells. Acta Ortop Bras. 2006;14(1):22-4.

10- Rezapour A, Majidi J. An improved method of neutrophil isolation in peripheral blood of sheep. J Anim Vet Adv. 2009;8(1):11-5.

11- Hashemi M, Ghavami S. Effects of estradiol, progesterone and testosterone on proliferation of human breast cancer cell lines. Tabib-E-Shargh. 2005;7(1):21-9. [Persian]

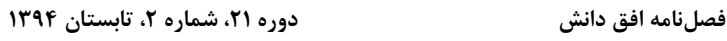

